\title{
Concepts of Adversity, Risk, Vulnerability and Resilience: A Discussion in the Context of the 'Child Protection System'
}

\author{
Brigid Daniel
}

Department of Applied Social Science, University of Stirling

E-mail: b.m.daniel@stir.ac.uk

This paper explores the concepts of adversity, risk, vulnerability and resilience in the context of child protection systems with the aim of contributing to the debate about the ways in which risk of 'harm' and 'abuse' are conceptualised at different stages of the lifespan and in relation to different groups of people. The recent developments in the policy and legislative framework for state intervention on behalf of children in the $U K$ are described and linked with an exploration of the underlying assumptions about abuse and neglect. Concepts of adversity, risk, vulnerability and resilience and the ways in which the complexity of the routes and pathways to 'harm' pose a challenge to the current UK state protective system are discussed.

\section{Introduction}

There is now a considerable body of evidence about the impact of abuse and neglect upon outcomes for children (Gilbert et al., 2009). This recognition of harm, coupled with the concept of children as inherently vulnerable, has provided the impetus for statutory systems for the protection of children from such harm. The state 'protective' systems across the UK are currently undergoing development and change in response to a range of political drivers, including a concern about the longer-term impact of abuse and neglect and other forms of adversity for individual children and for society as a whole. The change process has highlighted debates about the aims and focus of the 'protective' system. The current development of legislation and policy in relation to the protection of adults also prompts consideration of the extent to which the underpinning concepts are common to both. This paper discusses the concepts of adversity, risk, vulnerability and resilience in relation to the child protection system with the aim of contributing to the debate about the ways in which risk of 'harm' and 'abuse' are conceptualised at different stages of the lifespan and in relation to different groups of people.

Intervention into the privacy of family life is legitimated by legislation that is based upon the premise that children are vulnerable, that we cannot take it for granted that parents will always offer the appropriate protection and that they may, on occasion, actively harm their children. It could be argued that the demonstration of potential harm to children renders the need for a protective system unproblematic and, indeed, a moral imperative. However, in the context of child welfare and protection, the explicit and implicit definitions of 'adversity', 'risk' and 'vulnerability' can have profound effects upon understandings about the most appropriate policy and practice response. Legislation is based upon the premise that 'risk' of harm in the face of adversity can be assessed and 
quantified, but as will be described later, this is a problematic assumption. Challenges come from a critique of the assumptions of childhood as a distinct category characterised by inherent vulnerability. The evidence emerging from the study of 'resilience' poses further challenges to the fatalistic assumption that children's developmental pathways follow predictably negative trajectories in response to adversity. Such challenges have led some to suggest that the system itself has become part of the problem rather than the solution.

The concepts of adversity, risk, vulnerability and resilience are all rather slippery, especially when considered in relation to children and state protective systems. All can be defined quite broadly or quite narrowly and all can be subject to critique.

\section{Adversity}

For children, 'adversity' has been defined as 'the experience of life events and circumstances which may combine to threaten or challenge healthy development' (Daniel et al., 1999). The assumption underlying this statement is that children's developmental pathways can be adversely affected by a range of circumstances. The definition of these adverse factors can range from the narrow to the very broad including:

- incidents of physical or sexual abuse,

- traumatic incidents such as loss and bereavement,

- chronic situations - such as environments of neglect,

- experiences of bullying or racism,

- family stressors,

- structural inequalities and socio-economic disadvantages.

The current 'child protection' system in the UK, and in countries with similar welfare traditions, developed through the 1980s and 1990s. It shifted from one shaped by a 'sociomedical' discourse in which abuse was 'diagnosed' and therapeutic support was offered, towards a 'socio-legal' discourse with an emphasis upon the need for a statutory basis for intervention in family life and a forensic approach to the 'investigation' of allegations of abuse and neglect (Parton, 2008). The operation of the system was shaped by guidance that focused on fairly narrow definitions of the kind of adversity that could legitimate state intervention into family life - thus in England the categories used to shape multidisciplinary decisions are physical abuse, emotional abuse, sexual abuse and neglect (Department of Health and Department for Education and Employment, 2000) and in Scotland they are physical injury, sexual abuse, non-organic failure to thrive, emotional abuse and physical neglect (Scottish Executive, 2000).

Dissatisfaction with, and challenges to, these narrow definitions come from different directions. They include, for example, concerns that the system focuses too much on parental acts of commission or omission and deflects attention away from adversity resulting from wider state policy associated with socio-economic inequality and high levels of child poverty (Baldwin and Spencer, 2005). Such arguments are not so much a direct challenge to the operation of the child protection system within the narrow field of adversity defined for it, as a challenge to the assumption that it is a sufficient response to the needs of children. A more direct challenge to the operation of the 'child protection system' comes from bodies of research into the impact upon children's development of a wider range of domestic adversity. These include attention to the impact of male violence 
against women upon the children in a household (Hester et al., 2000; Mullender, 1996). This body of work has been sufficiently influential such that within the recent series of Lancet papers on maltreatment, 'intimate partner violence' is included as a separate category along with physical, sexual, psychological or emotional abuse and neglect. ${ }^{1}$ Research into the impact of emotional deprivation and chronic neglect upon brain and other physiological development has also been influential (Perry, 1997; Glaser, 2000). It is perhaps a testament to the power of our positivist scientific tradition that the evidence of physiological harm appears to lend more 'weight' to arguments for intervention than evidence of emotional harm. There has also been research into the impact upon children of parental substance misuse (Barnard and Barlow, 2003), parental mental ill-health (Falkov, 1996) or combinations of such factors (Cleaver, 1999). Perhaps because they stem from the domestic arena, all these identified factors have acted to 'stretch' the concepts of adversity that are traditionally called upon within the child protection system; or, seen from another angle, these adversities have been pushed and pulled so that they can 'fit' with the categories above - often 'emotional abuse' appears to be the most convenient category.

Broader understandings of the adversities that impact upon children also imply different understandings of concepts of 'victim' and 'perpetrator'. For example, in situations of domestic abuse the perpetrator of violence to the mother is also rendered a perpetrator of child abuse and the child becomes a 'secondary' victim of a crime. If the focus is upon a child's unmet needs, then attention is on parental failure, usually constructed as maternal failure (Swift, 1995; Scourfield, 2003; Daniel et al., 2005). A focus on deprivation opens the potential for the state to be viewed as the perpetrator and children to be victims of state policies that fail to effectively tackle child poverty. All are a far step from the concept of the predatory sex abuser, which is the more familiar narrative of 'perpetrator'.

A more recent phenomenon is the re-defining of the 'child protection' system with a view to it being able to accommodate a wider range of adversities. As the range of identified adversities has widened, the focus of concern has broadened and become generalised under the umbrella of 'unmet needs' (DoH, 2000; DFES, 2004). Parton (2007, 2008) has undertaken a detailed analysis of New Labour's children's policies. He describes the shift in language from 'child protection' to 'safeguarding' as the focus shifts to unmet need, and he identifies the increasingly wide range of adversities it is considered that the state should be concerned about, including school exclusion, running away, involvement in crime and so on. This broadening of scope means that 'adversity' has spilled well beyond the operational categories defined for the 'child protection' system.

\section{Risk}

In the context of child protection, 'risk' denotes the chances of adversity translating into actual negative outcomes for children. In practice, it is used as shorthand for capturing an often ill-defined combination of issues including:

- the chances of a child experiencing a particular adverse circumstance;

- the chances of a child being sexually or physically abused, or re-abused;

- the chances of the parents or carers being unable (or unwilling) to ameliorate the impact of adversity; 
- the chances of the adverse experience having a significant negative impact upon wellbeing during childhood and

- the chances of longer-term negative outcomes as a result of experiencing adversity.

Like adversity, risk can also be defined narrowly or broadly:

In narrow definitions the emphasis is placed on individual events, for example a physical abuse incident ... in these situations risk is equated to harm and the negative outcomes of the event ... Whereas in the broader definitions, a more comprehensive assessment, based on ecological and feminist perspectives, is undertaken. (Waugh, 2008: 113)

In the narrow world of statutory 'child protection' activity, risk is inextricably tied in with concepts of harm, both acute forms of harm, such as physical injury, and more chronic forms, such as compromised global development as a result of neglect. It can be used both to denote the likelihood of abuse occurring and the likelihood of harm resulting from abuse.

The concept of risk brings a future focus and entails making predictions based upon weighing up probabilities. As Parton (2007) highlights, a future focus was first explicitly encapsulated in the legislative system in England and Wales in the late 1980s with the introduction of the criterion for intervention in the Children Act 1989 as 'that the child concerned is suffering, or is likely to suffer significant harm' (s.31(92)(a)). Similarly, section 52(2)(c) of the Children (Scotland) Act 1995 uses the term 'is likely ... to be impaired in his health or development'. The word 'likely' has been fraught with difficulties and has been the subject of much debate. On the one hand, it is would be difficult to maintain a position that intervention on behalf of a child should be delayed until actual harm has been experienced - to prevent harm occurring has to be viewed as a decent and reasonable response (Glaser, 2002). Indeed, prevention and early intervention are concepts that increasingly underpin children's services policies in many countries. On the other hand, this entails the need to assess the likelihood of future 'suffering', which is notoriously difficult.

One response to the problem has been the development of a range of risk-assessment tools, some of which aim to incorporate a predictive element (Browne and Saqui, 2002). But, given that human beings are poor at gauging probabilities, Munro (2007) suggests that we should not expect child protection workers to be 'fortune tellers'. She provides a detailed mathematical analysis of the accuracy (or rather, inaccuracy) of risk assessment instruments and one of the key messages from her analysis is that the rarer the event, the harder it is to predict with accuracy. The other key message is that factors associated with abuse are only moderate predictors, because of the extent to which non-abusing families share the same factors. Munro suggests that, even though actuarial methods have very poor predictive powers, they are still more useful than clinical judgement, which she suggests is even worse. The issue then hinges on the general public's tolerance for both false positives and false negatives. Some suggest that the unacceptably high levels of both false positives and false negatives in actuarial models means that their use is unhelpful (Appleton and Cowley, 2004) and even unethical (Taylor et al., in press).

Organisational contexts can also shape understandings of risk, not least risks to the organisation itself and to its staff that flow from the negative consequences of apparently taking the wrong decision in respect of risk. Dalgleish's (2003) model for decision-making 
in the context of risk explicitly includes the organisational tolerance of risk as one of the factors to be taken into account. He describes the ways in which organisational tolerance can fluctuate in the light of local inquiries into child deaths and recent experiences of apparently poor decisions. Parental definitions of risk may also be very different from professional definitions (Waugh, 2008). The risk of having a child removed may be more salient to parents than an ill-defined likelihood of harm in the future, should the child remain in their care. The range of different risks have been summarised by Cooper et al. (2003: 15):

There are both explicit and implicit risks: risks of intervention (trauma for children); risks of non-intervention (continued abuse); risks to third parties (siblings, neighbours); and risks to professionals (getting it wrong, stepping over organisational boundaries, misusing scarce resources).

Munro (2007) explores the ways that the concept of risk has moved from one with essentially neutral connotations to one where it is associated with negative outcomes. When viewed primarily in terms of bad outcomes, 'risk' essentially means the risk of bad outcomes resulting from the impact of adversity upon a vulnerable child. As she points out, we do not tend to talk about the 'risk' of a good outcome for a child. She suggests that this association with negative outcomes distorts decision-making in relation to child protection, such that the drive to avoid 'bad' outcomes is inextricably linked with the assessment of 'risk'. The focus on preventing negative outcomes means that we do not look at the aspect of promotion of well-being, rather only focus on minimising danger. Cooper et al. (2003) also suggest that risks in human settings, such as child protection, cannot be conceptualised in the same way as in other settings. They suggest that risk management models from arenas such as accountancy have been misapplied to child protection and that the focus on diagnosing risk works against the development of therapeutic approaches that depend on relationship-building and trust.

'Risk' has become a term that can be defined very narrowly, but in relation to child protection is used loosely and widely to denote a range of negative outcomes for children, parents, society, professionals and organisations. Thus, it does not provide a straightforward model for adoption in adult settings. When combined with concepts of adversity and vulnerability the picture becomes even more complex.

\section{Vulnerability}

Children are treated as a discrete group for the purposes of the UN Charter of children's rights, thus signalling their need for particular attention (United Nations, 1989). Many countries have specific legislation and guidance that applies to individuals who fall within a specific age-range from birth up to a cut-off point defined as the end of 'childhood'. The cut-off point varies according to different countries, and within countries may be different for different aspects of legislation. Nonetheless, there are protections accorded to a category considered to be 'children'. In addition, many countries have policies that target groups of children seen to be at elevated vulnerability because of the adverse circumstances that they are experiencing. In sum, vulnerability appears simultaneously to be conceptualised broadly and narrowly with a view that all children are vulnerable, but some are more vulnerable than others. 
It is the concept of children as especially 'vulnerable' that has legitimised the development of the forensic investigative child protection system. 'Vulnerability' is generally a highly contested term, and in regard to childhood in particular there are a range of possible positions about the extent to which children are conceptualised as vulnerable, merely by virtue of being children. Children may be viewed as vulnerable because of their size, their fragility when little and because they are still being 'formed'. An adverse factor is defined thus because it potentially compromises a child's healthy development, and it is the interaction between adversity and the developmental processes that is considered to be uniquely damaging. At the extremes, vulnerability may be clearcut: shaking an infant, for example, is more likely to inflict serious physiological damage than shaking a young adult. How, though, is vulnerability to be understood in cases where an adolescent young man physically assaults his mother? Similarly, is it possible to place the impact of sexual abuse on a hierarchy of trauma correlated with age such that it is always assumed to be more emotionally damaging to children than adults or older adults?

Perhaps the greatest challenge to the automatic assumption of childhood vulnerability comes from the sociology of childhood in which it is argued that the concept of childhood is socially constructed. Stainton Rogers, for example, suggests that 'there is no natural distinction that marks off children as a certain category of person. Rather, the category of 'a child' is just that - a category' (Stainton Rogers, 2001: 27). She describes two discourses about childhood: one that romanticises childhood as a time of innocence and another that assumes that children need to be socialised and to be taught morals. The common theme of both, though, is one of concern about children with an attendant adult responsibility for children. Thus the two discourses are recast within current UK policy as a 'discourse of welfare' and a 'discourse of control', with the former running though social policy and the latter through education policy. She raises questions as to whether the conceptualisation of children as passive recipients of our concern reduces them. Practitioners operating within the child protection system frequently override the wishes of children: for example, the volume of calls to ChildLine shows the extent to which children crave the confidentiality that the statutory system does not provide. There is an interesting resonance here with the powerful statement made by Dame Butler Sloss in her report into an Inquiry into child abuse investigations in Cleveland: 'the child should be seen as a person, not as an object of concern' (Butler-Sloss, 1998: 245). The dichotomy can also be seen in the ways in which children who commit violent crimes or who are seen as a threat to social order are constructed as 'perpetrators' rather than 'victims' and as no longer being in the 'child' category (Piper, 2008).

A further concern about the assumption of children as inherently vulnerable is that, in effect, it 'problematises' childhood (James, 2008). The names of the two key policy documents in the UK - Every Child Matters (DFES, 2004) and Getting it Right for Every Child (Scottish Executive, 2005) specifically signal a concern for all children. The common principle underlying these policies is the expectation that the universal services of health and education should play a role in ensuring that the range of needs of all children are identified and met. It could be argued that these policies signal recognition of children as people in their own right who should have access to all the services they need in order to thrive. On the other hand, Parton $(2007,2008)$ questions the direction of UK policy by suggesting that the broadening of concern to include all concerns about children's 
health and development is leading to increased regulation and surveillance of children as a group. He also suggests that this broadening of focus may be counter-productive by asking:

Does the combining of abuse with all other concerns about a child's health and development potentially harm the quality of child protection services and therefore the safety of children? (2007: 28)

It is further suggested that our current pre-occupation with protecting children as a group is actively damaging to children. Newman and Blackburn (2002) suggest that we are pre-occupied with risk and its avoidance, to the extent that children in general now have reduced opportunities to take risks and learn importance competencies. Therefore, by trying to eliminate risk we increase the risk of other poor outcomes, including poor psychological and physical health and poor coping skills (Newman and Blackburn, 2002). This argument may be influenced in part by the discourse of childhood as a time of innocence and freedom - the recent rise of concern about 'cotton wool kids' perhaps also captures a sense of adult concern about a lost world of freedom. Paradoxically, therefore, we can see that 'concern' about children as a group in need of specific attention because of their unique vulnerability can simultaneously signal a recognition that children should be accorded state protection but potentially de-humanise them and deny their role as active citizens in their own right.

\section{Resilience}

The population-based studies that link poor outcomes with abuse and neglect, coupled with the concept of children as especially vulnerable to the impact of abuse and neglect, act as powerful drivers and justification for a state protective system. However, the research into resilience poses real challenges for a system of 'protection' that is based upon the assumption of damage, because it shows that there are considerable individual differences in the extent of poor outcomes as a result of adversity. Resilience is defined as 'a phenomenon or process reflecting relatively positive adaptation despite experiences of adversity or trauma' (Luthar, 2005: 6).

One of the most influential studies of resilience was that of Werner who tracked the development of 698 children born in 1955 on Kauai (Werner and Smith, 1992). A third (201) of these children were considered to be at risk of poorer developmental outcomes. By the first decade, two out of three of those considered to be at high risk were showing learning and behaviour problems and, by 18, had mental health problems, delinquency records and/or teenage pregnancies. However, a third of the children predicted to be at high risk grew into what Werner defined as 'competent, confident and caring adults'. She and her team were particularly interested in the factors that were associated with better than predicted outcomes. For young children, school aged children and for adolescents they mapped the factors at the level of the individual, family and wider community that were associated with resilience. These include a cluster of personal characteristics such as self-efficacy, coupled with factors associated with secure attachments and relationships 
and resources in the school and wider community. Gilligan (1997:12) has summed these up as:

qualities which cushion a vulnerable child from the worst effects of adversity in whatever form it takes and which may help a child or young person to cope, survive and even thrive in the face of great hurt and disadvantage.

Resilience, therefore, can be seen as an emergent property from the experience of adversity and the demonstration of relatively good outcomes. However, resilience is also a concept that is somewhat slippery, especially with regard to definitions of adversity and of good outcomes. For the purposes of empirical research, adversity is normally defined by the researchers, but different studies use different measures. Some define adversity in terms of constellations of experiences, such as poor socio-economic circumstances, poorly resourced neighbourhoods (Sameroff et al., 2003); others focus on a particular adversity, such as parental depression (Hammen, 2003) or parental divorce (Hetherington and Mitchell Elmore, 2003). This variation makes studies hard to compare, but it also means that studies are not routinely incorporating attention to the ways in which children and young people subjectively construct stressful events and adversity (Gore and Eckenrode, 1994). One person's stressor may be another person's challenge. The concept has also been criticised as individualising what should be seen as structural adversities and as contributing to an individualistic notion that children and young people can overcome any difficulty if they try hard enough (Rigsby, 1994). Despite the criticisms, the consistent findings that different children respond differently to adversity and that negative outcomes cannot always be predicted poses challenges to a child protection system that is underpinned by risk assessment.

\section{Conclusion}

The concept of using legislation to underpin state powers for the protection of children has been well-established in the UK since the 1960s and developed in response to heightened awareness of the 'battered child syndrome' (Kempe et al., 1962). To those developing legislation, policies and procedures for the protection of adults, the child protection system may appear to be well-established and to provide a helpful model. However, the child protection system has always been subject to tensions, and, interestingly, the rise in concern about the protection of adults has sharpened the need to consider its underlying assumptions. In particular, the broadening of the range of adversities that are identified as likely to impact on children's optimal development has challenged a system that was originally designed to deal with more narrowly defined incidences of maltreatment. Adversities such as parental mental ill-health, poverty or school exclusion do not lend themselves to a forensic, investigative approach. Current policy initiatives recognise this. The aim is that the majority of identified unmet need be responded to early and on a voluntary basis, thus reserving statutory investigative processes for more serious manifestations of entrenched abuse or neglect. However, there remain unanswered questions about the boundary between the universal approach that focuses on wider adversities and a parent culpability approach that focuses on omission of care or active commission of acts that cause harm. 
Nonetheless, current UK policy is still underpinned by assumptions of children as especially vulnerable to the impact of abuse and neglect, as at elevated risk of poor outcomes as a result of adversity, and requiring a discrete set of protective measures. Children are regarded as a separate group and they are still 'objects of concern'. Messages from the sociology of childhood, coupled with the evidence from studies of resilience, suggest that there is need to give greater recognition to children's agency. Further, the observation that a focus on risk leads to risk aversion suggests that by trying to protect children from any harmful experiences we are in danger of the unintended consequences of limiting opportunities for growth and development.

As adult protection systems develop, and as the swathe of policy and guidance for the protection of children and of adults proliferate, we may be approaching a time where we need to stand back from the systems we have and ask whether there is a need to re-think them. Rather than trying to delineate the relative impact of adversity at different ages and rather than attempting to refine tools to capture the risk of that impact being negative, it may be more fruitful to develop some key principles for practice that could be applied to any individual, regardless of their chronological age.

\section{Acknowledgements}

The author acknowledges funding from the Economic and Social Research Council for the seminar series which enabled this paper to be presented.

\section{Note}

$1 \mathrm{http} / / /$ www.thelancet.com/series/child-maltreatment

\section{References}

Appleton, J. V. and Cowley, S. (2004), 'The guideline contradiction: health visitors' use of formal guidelines for identifying and assessing families in need', International Journal of Nursing Studies, 41, 7, 78597.

Baldwin, N. and Spencer, N. J. (2005), 'Economic, cultural and social contexts of neglect', in J. Taylor and B. Daniel (eds.), Child Neglect: Practice Issues for Health and Social Care, London: Jessica Kingsley Publishers.

Barnard, M. and Barlow, J. (2003), 'Discovering parental drug dependence: silence and disclosure', Children and Society, 17, 1, 45-56.

Browne, K. and Saqui, S. (2002), 'Approaches to screening for child abuse and neglect', in K. Browne, H. Hanks, P. Stratton and C. Hamilton (eds.), Early Prediction and Prevention of Child Abuse, Chichester: Wiley.

Butler-Sloss, E. (1998), Report of the Inquiry into Child Abuse in Cleveland 1987, London: HMSO.

Cleaver, H. (ed.) (1999), Children's Needs: Parenting Capacity and the Impact of Parental Mental Illness, Problem Alcohol, Drug Use and Domestic Violence on Children's Development, London: HMSO.

Cooper, A., Hetherington, R. and Katz, I. (2003), The Risk Factor: Making the Child Protection System Work for Children, London: DEMOS.

Dalgleish, L. (2003), 'Risks, needs and consequences', in M. Calder and S. Hackett (eds.), Assessment in Child Care: Using and Developing Frameworks for Practice, Dorset: Russell House Publishing.

Daniel, B., Featherstone, B., Hooper, C. -A. and Scourfield, J. (2005), 'Why gender matters for Every Child Matters', British Journal of Social Work, 35, 8, 1343-56. 
Daniel, B., Wassell, S. and Gilligan, R. (1999), Child Development for Child Care and Protection Workers, London: Jessica Kingsley Publishers.

Department of Health (2000), Framework for the Assessment of Children in Need and Their Families, London: The Stationery Office.

Department of Health and Department for Education and Employment (2000), Working Together to Safeguard Children: A Guide to Inter-Agency Working to Safeguard and Promote the Welfare of Children, London: The Stationery Office.

DFES (2004), Every Child Matters: Change for Children, London: The Stationery Office.

Falkov, A. (1996), A Study of Working Together Part 8 Reports: Fatal Child Abuse and Parental Psychiatric Disorder, London: Department of Health.

Gilbert, R., Spatz Widom, C., Browne, K., Fergusson, D., Webb, E. and Janson, S. (2009), 'Burden and consequences of child maltreatment in high-income countries', The Lancet, advance publication, http://www.thelancet.com/series/child-maltreatment.

Gilligan, R. (1997), 'Beyond permanence? The importance of resilience in child placement practice and planning', Adoption and Fostering, 21, 1, 12-20.

Glaser, D. (2000), 'Child abuse and neglect and the brain - a review', Journal of Child Psychology and Psychiatry, 41, 1, 97-116.

Glaser, D. (2002), 'Emotional abuse and neglect (psychological maltreatment): a conceptual framework', Child Abuse and Neglect, 26, 6-7, 697-714.

Gore, S. and Eckenrode, J. (1994), 'Context and process in research on risk and resilience', in R. J. Haggerty, L. R. Sherrod, N. Garmezy and M. Rutter (eds.), Stress, Risk and Resilience in Children and Adolescents: Processes, Mechanisms, and Interventions, Cambridge: Cambridge University Press.

Hammen, C. (2003), 'Risk and protective factors for children of depressed parents', in S. Luthar (ed.), Resilience and Vulnerability, New York: Cambridge University Press.

Hester, M., Pearson, C. and Harwin, N. (2000), Making an Impact: Children and Domestic Violence, London and Philadelphia: Jessica Kingsley.

Hetherington, E. M. and Mitchell Elmore, A. (2003), 'Risk and resilience in children coping with their parents' divorce and remarriage', in S. Luthar (ed.), Resilience and Vulnerability, New York: Cambridge University Press.

James, A. (2008), 'Power, participation and citizenship in the lifecourse', L. C. R. G. K. Seminar, Stirling University, Stirling.

Kempe, C. H., Silverman, F. N., Steele, B. F., Droegemuller, W. and Silver, H. K. (1962), 'The battered child syndrome', Journal of the American Medical Association, 181, 1, 17-24.

Luthar, S. (2005), 'Resilience in development: a synthesis of research across five decades', in D. Cicchetti and D. J. Cohen (eds.), Development Psychopathology: Risk, Disorder and Adaptation, New York: Wiley.

Mullender, A. (1996), Rethinking Domestic Violence: The Social Work and Probation Response, London and New York: Routledge.

Munro, E. (2007), Child Protection, London and Thousand Oaks, CA: Sage Publications.

Newman, T. and Blackburn, S. (2002), Transitions in the Lives of Children and Young People: Resilience Factors, Edinburgh: Scottish Executive Education Department.

Parton, N. B. (2007), 'Safeguarding children: a socio-historical analysis', in K. Wilson and A. James (eds.), The Child Protection Handbook, Philadelphia: Bailliere Tindall, Elsevier, pp. 9-30.

Parton, N. (2008), 'Towards the "preventive-surveillance state"', in K. Burns and D. Lynch (eds.), Child Protection and Practice Perspectives, Dublin: A. and A. Farmer Ltd.

Perry, B. (1997), 'Incubated in terror: neurodevelopmental factors in the "cycle of violence"', in J. D. Osofsky (ed.), Children in a Violent Society, New York: Guildford Publications.

Piper, C. (2008), Investing in Children: Policy, Law and Practice in Context, Uffculme: Willan Publishing.

Rigsby, L. C. (1994), 'The Americanization of resilience: deconstructing research practice', in M. C. Wang and E. W. Gordons (eds.), Educational Resilience in Inner-City America: Challenges and Prospects, Hillsdale, NJ: Lawrence Erlbaum. 
Sameroff, A., Gutman, L. and Peck, S. C. (2003), 'Adaptation among youth facing multiple risks: prospective research findings', in S. Luthar (ed.), Resilience and Vulnerability, New York: Cambridge University Press.

Scottish Executive (2000), Protecting Children - A Shared Responsibility: Guidance for Health Professionals in Scotland, Edinburgh: The Stationery Office.

Scottish Executive (2005), Getting It Right For Every Child, Edinburgh: Scottish Executive.

Scourfield, J. (2003), Gender and Child Protection, Houndsmills: Palgrave Macmillan.

Stainton Rogers, W. (2001), 'Constructing childhood, constructing child concern', in P. Foley, J. Roche and S. Tucker (eds.), Children in Society, Hampshire and New York: Palgrave with the Open University.

Swift, K. J. (1995), Manufacturing 'Bad Mothers': A Critical Perspective on Child Neglect, Canada: University of Toronto Press.

Taylor, J. S., Baldwin, N. and Spencer, N. (in press), 'Predicting child abuse and neglect: ethical, theoretical and methodological challenges', Journal of Clinical Nursing.

United Nations (1989), United Nations Convention on the Rights of the Child, New York: General Assembly of the United Nations.

Waugh, F. (2008), 'Violence against children within the family', in B. Fawcett and F. Waugh (eds.), Addressing Violence, Abuse and Oppression: Debates and Challenges, New York: Routledge.

Werner, E. E. and Smith, R. S. (1992), Overcoming the Odds: High Risk Children from Birth to Adulthood, Ithaca and London: Cornell University Press. 